\title{
Immunodeficiency due to a classical component pathway complement deficiency
}

INSERM

\section{Source}

INSERM. (1999). Orphanet: an online rare disease and orphan drug data base.

Immunodeficiency due to a classical component pathway complement deficiency.

ORPHA:169147

Immunodeficiency due to a classical component pathway complement deficiency is a primary immunodeficiency due to a deficiency in either complement components C1q, C1r, C1s, C2 or C4 characterized by increased susceptibility to bacterial infections, particularly with encapsulated bacteria, and increased risk for autoimmune disease. Most commonly, these include systemic lupus erythematosus (SLE), SLE-like disease, HenochSchonlein purpura, polymyositis and arthralgia. Disease severity is variable and dependent on the complement affected. 